\title{
LXIII. Slow transformation products of radium
}

\section{E. Rutherford F.R.S.}

To cite this article: E. Rutherford F.R.S. (1904) LXIII. Slow transformation products of radium , Philosophical Magazine Series 6, 8:47, 636-650, DOI: 10.1080/14786440409463234

To link to this article: http://dx.doi.org/10.1080/14786440409463234

册 Published online: 08 Jun 2010.

Submit your article to this journal $\pi$

Џll Article views: 8

Q View related articles ¿

Citing articles: 5 View citing articles $\sqsubset$ 


\section{[ 636 ]}

LXIII. Slow Transformation Products of Radium. By E. Rutherford, F.R.S., Macdonald Professor of Physics, McGill University, Montreal *

$\mathbf{I}^{\mathrm{T}}$ has been previously shown $\dagger$ that radium undergoes disintegration through a series of well marked stages. The radium first of all produces the radium emanation, and this in turn is transformed into an active deposit, which behaves as a solid, and gives rise to the phenomena of excited activity. I have recently shown that this active deposit undergoes three further rapid transformations $\ddagger$. For convenience, the products in the active deposit will be termed Radium A, Radium B, and Radium C respectively \$. The change from $A$ to $B$ is accompanied by $\alpha$ rays alone, the change $\mathrm{B}$ into $\mathrm{C}$ is a rayless change, while the change $\mathrm{C}$ into $\mathrm{D}$ gives rise to $\alpha, \beta$, and $\gamma$ rays. The time $\mathrm{T}$ for each of the products of radium to be half transformed is shown in the following table :-

\begin{tabular}{|c|c|c|}
\hline & T. & RaYs. \\
\hline RadiUM $\ldots \ldots \ldots \ldots \ldots$ & $\ldots \ldots$ & $\alpha$ rays. \\
\hline Radruar Emanation .. & 4 days & $\propto$ rays. \\
\hline Radium $A\} \ldots \ldots \ldots$ & 3 minutes & ¿ rays. \\
\hline $\left.\operatorname{RaDIUMI}_{\downarrow} \mathbf{B}\right\} \begin{array}{l}\text { Active } \\
\text { deposit }\end{array} \ldots$ & 21 minutes & no rays. \\
\hline RaDIUM C & 28 minutes & $\alpha, \beta, \gamma$ rays. \\
\hline
\end{tabular}

The changes in radium are not, however, completed at this stage, for it will be shown that there is very strong evidence that there are at least two more slow transformations.

M. and Mme. Curie \| observed that a body exposed in the presence of radium emanation did not, after removal, completely lose all its activity. A residual activity always remained, which they state was of the order of $1 / 20,000$ of the initial activity. It will be seen later, however, that the magnitude of this residual activity depends not only on the amount of emanation to which the body has been exposed, but also on the time of exposure. For an exposure of several

* Communicated to the International Electrical Congress, St. Louis, Sept. 16, 1904. Communicated by the Author.

† Rutherford and Soddy, Phil. Mag. April \& May 1903.

I Bakerian Lecture, Roy. Soc. Lond. 1904.

$\$$ Note.-The term emanation $\mathrm{X}$, which I previously employed to designate the matter Radium $A$, is not very suitable, and I have discarded it in favour of the present nomenclature, which is simple and elastic.

\|I Thèses presentées à la Facultê des Sciences, Paris, 1903, p. 116. 
hours, the residual activity is less than one millionth of the activity immediately after removal. Giesel* also observed that a platinum wire, after exposure to the emanation, showed residual activity which, he states, consists only of $\alpha$ rays.

An account will now be given of some investigations made by the writer on the nature of this residual activity and the chemical properties of the active matter itself. It is first of all necessary to show that the residual activity arises in consequence of a deposit of radioactive matter, and is not due to some action of the intense radiations to which the body made active has been subjected.

The inside of a long glass tube was covered with equal areas of thin metal, including aluminium, iron, copper, silver, lead, and platinum. A large amount of radium emanation was introduced into the tabe, and the tube closed. After seven days the metal plates were removed, and, after allowing two days to elapse for the ordinary excited activity to disappear, the residual activity of the plates was tested by an electrometer. The activity of the plates was found to be unequal, being greatest for copper and silver, and least for aluminium. The activity of copper was twice as great as that of aluminium. After standing for another week, the activity of the plates was again tested. The activity of each had diminished in the interval to some extent, but the initial differences observed had to a large extent disappeared. After reaching a minimum value the activity of each plate slowly but steadily increased at the same rate. After a month's interval the activity of each of the plates was nearly the same, and over three times the minimum value. The initial irregularities in the decay curves of the different metals are, in all probability, due to slight but different degrees of absorption of the radium emanation by the metal plates, the absorption being greatest for copper and silver and least for aluminium. As the occluded emanation was slowly released or lost its activity, the activity of the metal fell to a limiting value. The absorption of the radium emanation by lead, paraffin, and caoutchouc was some time ago observed by Curie and Danne + .

The residnal activity on the plates comprised both $\alpha$ and ' $\beta$ rays, the latter being present, in all cases, in a very unusual proportion. The equality of the activity and the identity of the radiation emitted from each plate shows that the residual activity is due to changes of some form of matter deposited on the plates, and that it cannot be ascribed to an action of

*. Berichte d. D. Chem. Gesell. p. 2368 (1903).

+ Comptes Rendus, cxxxvi. p. 364 (1903).

Phil. Mag. S. 6. Vol. 8. No. 47. Nov. 1904. 
the intense radiations ; for if such were the case, it would be expected that the activity produced on the different plates would vary not only in quantity, but also in quality. This result is confirmed by the observation that the active matter can be removed from a platinum plate by solution in sulphuric acid, and bas other distinctive chemical and physical properties.

The variation of the residual activity with time will first be considered. A platinum plate was exposed in the presence of the radium emanation for seven days. The amount of emanation initially present was equal to that obtained from about 3 milligrams of pure radium bromide. The plate immediately after removal gave a saturation-current, measured between parallel plates by a galvanometer, of $1.5 \times 10^{-7}$ ampere. For some hours after removal the activity decayed according to an exponential law with the time, falling to half value in 28 minutes. Three days after removal the active plate gave a saturation-current, measured by an electrometer, of $5 \times 10^{-13}$ ampere ; $i$. e., $1 / 300,000$ of the initial activity. The activity was observed to increase steadily with the time.

Fig. 1.

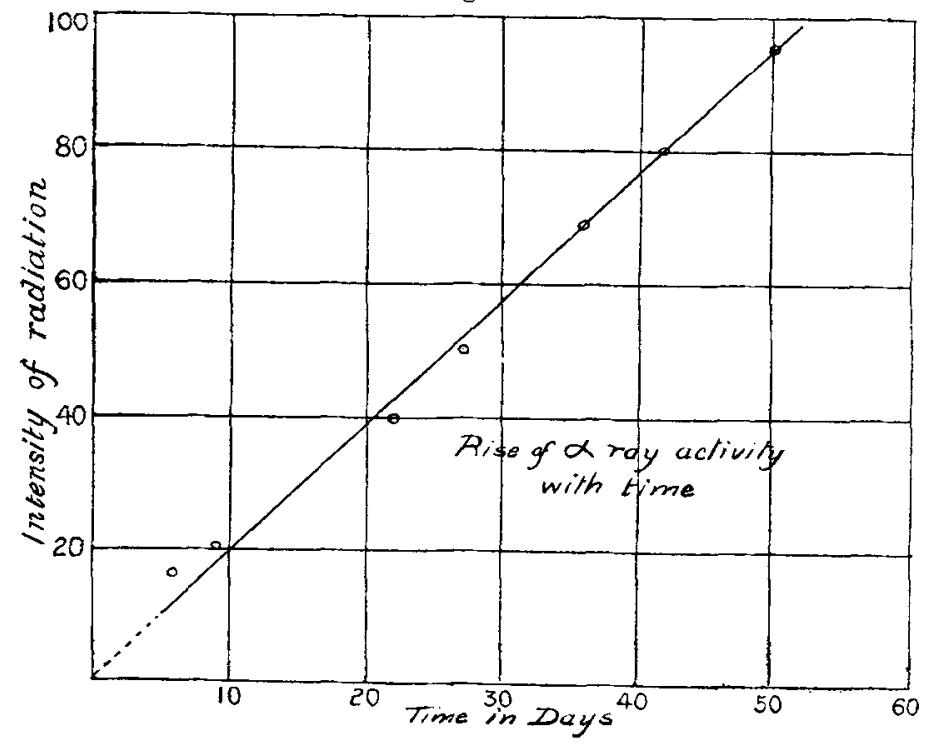

The results are shown in fig. 1 , where the time is reckoned from the middle of the time of exposure to the emanation.

The curve is a straight line passing through the origin. The activity increases uniformly with the time for the 
interval of two months over which the observations have extended.

Some results indicate that this steady increase with time continues for at least nine months. The emanation from 30 milligrams of radium bromide was condensed in a glass tube, which was then sealed. After a month's interval the tube was opened, and dilute sulphuric acid introduced. The acid dissolved the active residuo deposited in the tube. On driving off the sulphuric acid by heat, a radioactive deposit was obtained. The first determination of the activity of this residue was made about six weeks after the introduction of the emanation. The activity eight months later' was found to be about seven times the initial value. The results could not be very accurately obtained, as a portion of the activity had been removed in the interval by a bismuth rod placed in a solution of the active matter. The result, however, indicated that the activity had steadily increased over a period of nine months.

\section{Radiations from the Active Matter.}

The residual activity consists of both $\alpha$ and $\beta$ rays, the latter being present initially in an unusually large proportion. The proportion of $\alpha$ to $\beta$ rays from the platinum plate, one month after removal, was at the most one fiftieth of that from a thin film of radium bromide in radioactive equilibrium. Unlike the a ray activity, the activity measured by the $\beta$ rays remains constant, and, in consequence, the proportion of $\alpha$ to $\beta$ rays steadily increases with the time. The experiments showed that the intensity of the $\beta$ rays did not vary much, if at all, over a period of nine months. The want of proportionality between the $\alpha$ and $\beta$ rays shows that the two types of rays arise from different products. This conclusion is confirmed by experiments, now to be described, which show that the products giving rise to $\alpha$ and $\beta$ rays can be temporarily separated from one another by physical and chemical means.

\section{Effect of Temperature on the Activity.}

An active platinum plate was exposed to varying temperatures in an electric furnace, and the activity tested after exposure at atmospheric temperature. Four minutes' exposure in the furnace, at first at $430^{\circ} \mathrm{C}$., and afterwards at $800^{\circ} \mathrm{C}$., had little, if any, effect on the activity. After four minutes at $1000^{\circ} \mathrm{C}$. the activity decreased about 20 per cent., and a further exposure of eight minutes at a temperature of abont $1050^{\circ} \mathrm{C}$. almost completely removed the $\alpha$ ray activity. $2 \mathrm{Y}_{2}$ 
The activity recovered by the $\beta$ rays was, on the other hand, not appreciably changed by the high temperature. Further heating, however, at a still higher temperature, caused a decrease of the activity measured by the $\beta$ rays, showing that the $\beta$ ray product was also volatile. These results show that the active matter consists of two kinds. The part which emits $\beta$ rays is non-volatile at $1000^{\circ} \mathrm{C}$., but the other part which emits $\alpha$ rays is almost completely volatilized at that temperature.

\section{Separation of the Constituents by means of a Bismuth Plate.}

The active matter of slow decay was obtained in solution by introducing dilute sulphuric acid into a glass tube in which the emanation from 30 milligrams of radium bromide had been stored for a month. The solution showed strong activity and gave out both $\alpha$ and $\beta$ rays, the latter, as in other cases, being present in an unusually large proportion.

When a polished bismuth disk was kept for some hours in the solution, it became strongly active. The active matter deposited on the bismuth gave out $\alpha$ rays, but no trace of $\beta$ rays. After several bismuth disks had been successively left in the solution, the active matter, which emits $\alpha$ rays, was almost completely removed. This was shown by evaporating down the solution after treatment. The $\beta$ ray activity remained unchanged, but the. $\alpha$ ray activity had been reduced to about 10 per cent. of its original value. The active matter deposited in the bismuth does not appreciably change in activity in the course of one month, and some observations point to the conclusion that there is not much change in five montbs. The observations in the latter case were, however, not precise enough to be sure that there was not a small percentage variation during that time. Experiments are now in progress to examine, with accuracy, the activity of the bismuth plate from time to time, and it is hoped that observations extending over the ensuing year: will fix the rate of decay of this product, provided the rate of change is rapid enough to be measurable in a year's interval. The results obtained in this way are in agreement with those deduced by heating the active deposit to a high temperature. The active deposit contains two kinds of matter, viz. :-

(1) A product giving out only $\beta$ rays, which is soluble in sulphuric acid, but non-volatile at $1000^{\circ} \mathrm{C}$, and which is not deposited on bismuth.

(2) A product giving out only a rays, which is soluble in sulphuric acid, volatile at $1000^{\circ} \mathrm{C}$., and is deposited from a solution on bismuth. 
Explanation of the Results.

We have seen that the $\alpha$ ray activity increases if the $\beta$ ray product is present, but remains sensibly constant or changes very slowly if the $\alpha$ ray product is removed from the $\beta$ ray product by the action of a bismuth plate. The $\beta$ ray activity remains sensibly constant independently of whether the a ray product is present or not. These results show that the $\beta$ ray product is the parent of the a ray product. The amount of residual activity from the radium emanation depends on the amount of emanation present and the time of exposure to the emanation. These results show that the active deposit of slow decay is a decomposition product of the emanation, and, since the first three transition products of the emanation, viz. radium $A$, radium $B$, and radium $C$, have been carefully analysed and shown to be consecutive, it is natural to suppose that the matter of slow rate of change is a product of the last rapid change in radium $\mathrm{C}$.

Following the nomenclature suggested, radium ( $Y$ gives rise to the $\beta$ ray product, which will be called radium $D$, while radium $D$ changes into the $\alpha$ ray product, which will be called radium $\mathrm{E}$. The product radium $\mathrm{D}$ gives out only $\beta$ rays. The transition products of the disintegration of radium are shown diagrammatically in fig. 2 .

\section{Fig. 2.}
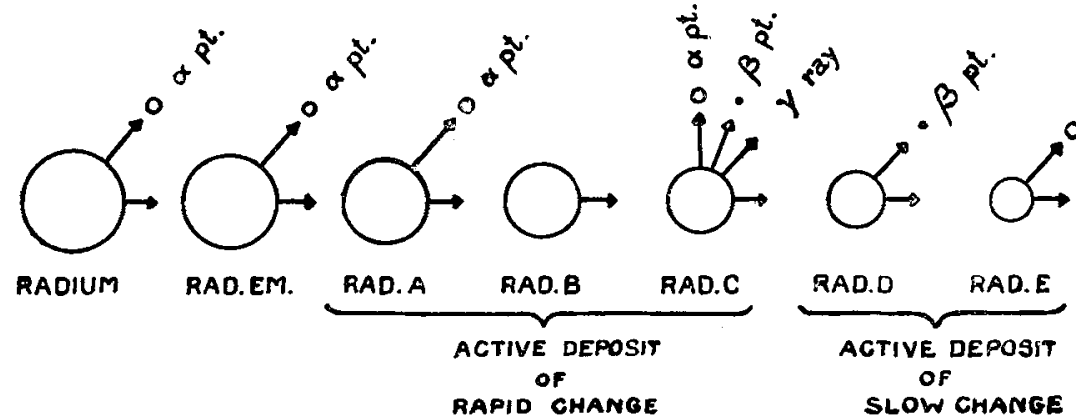

No further changes have so far been observed. The active solution of radium $\mathrm{D}$ and $\mathrm{E}$ was tested to see if an emanation were present. A trace of the radium emanation was always observed, but this was probably due to a slight trace of radium carried over into the emanation vessel. This point is, however, under further investigation.

\section{Theory of two Successive Changes.}

In all cases of radioactive change that have been examined, the amount of unchanged matter $\mathrm{N}_{t}$ present at any time $t$ is 
given by $\frac{\mathrm{N}_{t}}{\mathrm{~N}_{0}}=e^{-\lambda t}$, where $\mathrm{N}_{0}$ is the amount initially present, and $\lambda$ is the constant of change. Differentiating, $\frac{d N_{t}}{d t}=-\lambda N_{t}$, or the rate of change is always proportional to the amount present.

Suppose that $P_{0}$ particles of the product radium $D$ are deposited during the time of exposure to the emanation. This time is supposed to be so short that the amount of change of radium $\mathrm{D}$ during the time of exposure is very small.

Let $\mathrm{P}=$ number of particles of matter radium $\mathrm{D}$ present at any time.

$Q=$ number of particles of radium $E$ present at any time.

$\lambda_{1}=$ constant of change of radium D.

$\lambda_{2}=$ constant of change of radium $\mathrm{E}$.

Then $\mathrm{P}=\mathrm{P}_{0} e^{-\lambda_{1} t}$.

As the matter $D$ changes into $E$, the value of $Q$ at first increases. The increase $d \mathrm{Q}$ in the time $d t$ is given by the difference between the number of particles of $\mathrm{E}\left(\lambda_{1} \mathrm{P}\right)$ supplied by the change of $D$ into $E$ and the number of $E\left(\lambda_{2} Q\right)$ which change into $\mathrm{F}$.

Then

and

$$
d \mathrm{Q}=\lambda_{1} \mathrm{P} d t-\lambda_{2} \mathrm{Q} d t
$$

$$
\frac{d \mathrm{Q}}{d t}=\lambda_{1} \mathrm{P}_{0} e^{-\lambda_{1} t}-\lambda_{2} \mathrm{Q} \text {. }
$$

The solution of the equation is of the form:

$$
\mathrm{Q}=a e^{-\lambda_{1} t}+l_{1} e^{-\lambda_{2} t} \text {. }
$$

Since $Q=0$ when $t=0$, we have

and

$$
a=-b=\frac{\lambda_{1}}{\lambda_{2}-\lambda_{1}} \cdot \mathrm{P}_{0}
$$

$$
\mathrm{Q}=\frac{\lambda_{1} \mathrm{P}_{0}}{\lambda_{2}-\dot{\lambda}_{1}^{-}}\left(e^{-\lambda_{1} t}-e^{-\lambda_{2} t}\right) \text {. }
$$

For small values of $t, Q=\lambda_{1} P_{0} . t$; i. e., the value of $Q$ increases proportionately with the time. The value of $Q$ passes through a maximum at a time $\mathrm{T}$, given by $e^{\left(\lambda_{2}-\lambda_{1}\right) \mathrm{T}}=\frac{\lambda_{2}}{\lambda_{1}}$, and then decreases with the time.

The initial increase of the $\alpha$ ray activity with the time is thus in agreement with the view that radium $\mathrm{E}$ (which emits only a rays) is produced from radium $D$. The time of observation (two months) has not yet been long enough to obtain 
more than the initial part of the $\alpha$ ray curve. The results, however, show that an interval of two months is very short compared with the time required for the product $\mathrm{D}$ or $\mathrm{E}$ to be half transformed.

Although the times of observation have been too short to determine experimentally either the value of $\lambda_{1}$ or $\lambda_{2}$, it is possible, on certain assumptions, to form a rough estimate of these values.

It has been experimentally observed that each of the products of radium which emit $\alpha$ rays supplies about an equal proportion of the activity of radium when in radioactive equilibrium. Since, when equilibrium is reached, the same number of particles of each of the successive products must break up per second, this is an expression of the fact that every atom of each product breaks up with the expulsion of an equal number (probably one) of a particles. Now radium $D$ is directly derived from radium $C$, and since the rate of change of $\mathrm{D}$ is very slow compared with that of $\mathrm{C}$, the number of particles of $\mathrm{D}$ initially present must be very nearly equal to the number of particles of radium $\mathrm{C}$ which break up during the time that radium $D$ is being tormed. Now, suppose that each atom of radium $C$ and $D$ emits one $\beta$ particle with the same velocity. The ionization produced by each particle will be the same under the same experimental conditions, and the integrated value of the saturation current due to the $\beta$ rays over the time that the body is exposed to radium $\mathrm{C}$ must equal the corresponding integrated value for the $\beta$ rays during the life of radium D. Suppose, for example, that a quantity of emanation is introduced into a glass tube and left to stand for a month. During that interval the emanation has nearly all been transformed. The activity due to the $\beta$ rays from it will reach a maximum several hours after the introduction of the emanation, and will then decay with the time falling to half value in four days. Let $i_{1}$ be the maximum saturation current due to the $\beta$ rays, measured in a suitable testing vessel. The total quantity $Q_{1}$ of electricity passing between the plates of the testing vessel during the life of the emanation is approximately given by

$$
\mathrm{Q}_{1}=\int_{0}^{\infty} i d t=\int_{0}^{\infty} i_{1} e^{-\lambda t} d t={ }_{\lambda}^{i_{1}},
$$

where $\lambda$ is the constant of change of the emanation.

In a similar way, if $i_{2}$ is the initial current due to the $\beta$ rays from the radium $D$ deposited in the tube (measured 
under identical experimental conditions) the corresponding value of $Q_{2}=\frac{i_{2}}{\lambda_{1}}$ where $\lambda_{1}$ is the constant of change of $\mathrm{D}$.

Since by hypothesis $Q_{1}=Q_{\hat{2}}$,

$$
\frac{\lambda_{1}}{\lambda}=\frac{i_{2}}{i_{1}} .
$$

The ratio $\frac{i_{2}}{i_{1}}$ is determined experimentally, and since $\lambda$ for the emanation is known, $\lambda_{1}$ is determined.

The details of the experiments by which the ratio $i_{2} / i_{1}$ was determined need not be given here. It was deduced on the above assumption, that half of the matter of radium $D$ should be transformed in forty years. In a similar way, the total number of a particles expelled from radium $C$ during the time radium $D$ was being deposited must equal the number of a particles expelled from radium $E$ during its life, supposing that there is only one change which gives rise to a rays. Assuming for the moment that the a ray activity, observed for the active deposit ten months old, decayed from that time according to an exponential law, it was calculated that the period of the change could not be longer than eighty years. If the a ray change has a period short compared with the $\beta$ ray change, the $\alpha$ ray activity will finally decay at the same rate as the $\beta$ ray activity. These two computations will agree, if it is supposed that the $a$ ray activity increases to twice the value observed after an interval of ten months, and then decays with the time according to the period of the $\beta$ ray change. This would fix the period of the $\alpha$ ray change at about one year. When the $\alpha$ ray activity reaches its maximum value, it is to be expected, on this view, that the ratio $\frac{\alpha}{\beta}$ should be the same as for the product radium $\mathrm{C}$. This is, however, somewhat at variance with experiment; for the ten months old deposit has about the same ratio $\frac{\alpha}{\beta}$ as radium $\mathrm{C}$, while on the above computation the ratio $\frac{\alpha}{\beta}$ should only be one half of that value. This difference may possibly be due to radium $\mathrm{E}$ undergoing a further change, giving rise to $\alpha$ rays, which bas not so far been detected. In these calculations, it has been assumed that the $\alpha$ and $\beta$ particles given out in these slow changes produce the same ionization as the corresponding particles from radium C. There is no doubt, however, that 
this is not realized in practice. The $\beta$ rays of radium $D$ are slightly less penetrating than those of radium $C$, while the a rays of radium $\mathrm{E}$ have only about half the penetrating power of those of radium C. Our knowledge of the mechanism of absorption in matter is, however, too imperfect to correct for these differences with any certainty.

The above methods of calculation, though somewhat complicated, certainly serve to give the right order of magnitude of the periods of the two changes. It will be shown, too, that the calculated periods agree approximately with the amounts of radium $D$ and $E$ present in old samples of radium. The chief uncertainty in the methods of calculation lies in the difficulty of ascertaining the relative electrical effect produced by the $\alpha$ and $\beta$ particles compared with those emitted from radium C.

The time T required for each transition product of radium to be half transformed is shown in the following table :-

\begin{tabular}{|c|c|}
\hline $\begin{array}{l}\text { Transition } \\
\text { products of radium. }\end{array}$ & $\begin{array}{l}\text { Time 'I to be } \\
\text { half transformed. }\end{array}$ \\
\hline Ramign. & about 1000 years. \\
\hline Emanation. & 4 days. \\
\hline RADIUM $A$. & 3 minutes. \\
\hline Rabring $B$. & 21 minutes. \\
\hline RaDIUN $\mathrm{C}$ & \\
\hline $\begin{array}{l}\text { Radium D. } \\
\downarrow \\
\text { RaDiUM E. }\end{array}$ & about 40 years. \\
\hline
\end{tabular}

Experiments with Old Radium.

Since the substance radium $\mathrm{D}$ is produced from radium at a constant rate, the amount present mixed with the radium will increase with its age. I had in my possession a small quantity of my first specimen of impure radium chloride, kindly presented to me by Professors Elster and Geitel four years ago. The amount of radium $D$ present in it was tested in the following way:--The substance was dissolved in water and kept continuously boiling for a period of abont six hours. Under these conditions the emanation is removed as rapidly as it is formed, and the $\beta$ rays from the radium, due to the product radium $C$, practically disappear. A newly prepared specimen of radium bromide under these conditions retains only a fraction of 1 per cent. of its original $\beta$ radiation. 
The old radium, however, showed (immediately after this treatment) an activity measured by the $\beta$ rays of about 8 per cent. of its original amount. The activity could not be reduced any lower by further boiling or aspiration of air through the solution. This residual $\beta$ ray activity was due to the product radium $D$ stored up in the radium. It could not have been due to $\beta$ rays from radium $\mathrm{C}$, since there was a distinct difference in penetrating power for the two kinds of $\beta$ rays. The $\beta$ ray activity due to radium $D$ was thus about 9 per cent. of that due to radium $C$. Disregarding the differences in the absorption of the $\beta$ rays, when the activity of the product $D$ in radium reaches a maximum value, the $\beta$ ray activity due to it should be the same as that due to $C$. Since D is half transformed in forty years, the amount present in the radium after four years should be about 7 per cent. of the maximum amount; $i$. e., it should show a $\beta$ ray activity of about 7 per cent. of that due to radium $C$. The observed and calculated values ( 7 and 9 per cent. respectively) are thus of the same order of magnitude. The amount of $\beta$ rays from radium $D$ present in pure radium bromide about one year old was about 2 per cent. of the total.

The amount of radium $\mathrm{E}$ present in old radium was measured by observations of the activity imparted to a bismuth disk left for several days in the solution. Radium $\mathrm{E}$ is not deposited to an appreciable extent on the bismuth from a water solution of radium bromide. If, however, a trace of sulphuric acid is added to the solution, the radium $\mathrm{E}$ is readily deposited on the bismuth. The addition of sulphuric acid to the radium solution practically effected a separation of radium D and $E$ from the radium proper ; for the latter was precipitated as sulphate and the products D and $\mathrm{E}$ remained in solution. After filtering, the solution contained a greater proportion of the products $\mathrm{D}$ and $\mathbf{E}$ and very little radium.

The ratio $\alpha / \beta$ for the old radium was found to be about twice that observed for radium $C$. This result is in agreement with the deductions made in the calculations of the periods of the changes; for it can be theoretically shown that the amounts of $D$ and $E$ in the radium continue to be approximately proportional to one another after five years' production, assuming the periods of the changes are forty years and one year respectively.

The amounts of radium $D$ and $E$ observed in the old radium are thus in good agreement with the results deduced from other data. 


\section{Variation of the Activity of Radizm with Time.}

It has long been known that the activity of freshly prepared radium increases at first with the time and reaches a maximum value after an interval of about one month. The results already considered show that there is a further slow increase of activity with the time. This is the case whether the activity is measured by the $\alpha$ or $\beta$ rays. After a lapse of about 200 years the amount of the products radium D and $\mathrm{E}$ will have practically reached a maximum value. The same number of atoms of each of the products $\mathrm{C}$ and $\mathrm{I}$ will then break up per second. If each atom of these products in disintegrating throws off an equal number (probably one) of $\beta$ particles, the number of $\beta$ particles thrown off per second will be twice as great as from radium a few months old. The number will increase at first at the rate of about 2 per cent. a year.

Similar considerations apply to the a ray activity. Since, however, there are four other products of radium besides radium itself which expel a particles, the number of a particles emitted per second from old radium will not be more than 25 per cent. greater than the number from radium a few months old. The activity measured by the a rays will this not increase more than 25 per cent., and probably still less, as the a particles from radium $\mathbf{E}$ probably produce less ionization than the $\alpha$ particles expelled from the other radium products. It is probable that half of the radium itself is transformed in about 1000 years. The activity of radium will consequently rise to a maximum after 200 years and then slowly die away with the time.

\section{Products in Pitchblende.}

The products radium $\mathrm{D}$ and $\mathrm{E}$ must be present in pitchblende in amounts proportional to the quantity of radium present, and should be capable of separation from the mineral by suitable chemical methods. The radioactive properties of these substances, if obtained in the pure state, is summarized below.

Radium D.-The product immediately after separation should emit only $\beta$ (and probably $\gamma$ ) rays. The $\beta$ ray activity should decay to half value in about forty years. In consequence of the change of $D$ into $E$, the latter of which gives out a rays, the a ray activity will increase for a few years, pass through a maximum, and then decrease with the time and fall to half value in about forty years. Since the rate of change of $\mathrm{D}$ is about 25 times as fast as radium itself, 
the activity on separation, measured by the number of electrons expelled per second, should be 25 times as great as from an equal weight of radium. The a ray activity produced in it should at any time be capable of separation by adding a bismuth plate to a solution of the substance.

Radium E.-The substance should emit only $\alpha$ rays, and its activity should fall to half value in about one year. Since its rate of change is about 1000 times as great as radium, the substance, weight for weight, should emit about 1000 times as many a particles as freshly prepared radium, and about 250 times as many as from radium about one month old. The activity measured by the electric method will probably be about 100 times as great as that of pure radium.

It is now necessary to consider the question whether the substances radium $\mathrm{D}$ and $\mathrm{E}$ have been previously separated from pitchblende, and are known by other names. In regard to radium $\mathrm{D}$, there is some doubt whether it has been previously separated. It is possible that it is the radioactive constituent present in the radio-lead of Hoffimann, for he states that this substance emits a large amount of $\beta$ rays. On the other hand, the radio-lead prepared by other observers lost its activity rapidly with the time.

In regard to radium $\mathrm{E}, \mathrm{I}$ think there is little doubt that it is the radioactive constituent present in the so-called radiotellurium of Marckwald*. It will be recalled that Marckwald obtained a deposit of radioactive matter on a bismuth plate introduced into a solution of pitchblende. This active bismuth gave out only $\alpha$ rays. The active matter was associated with tellurium and was, in consequence, called radio-tellurium. In later observations Marckwald has show $n$ that tellurium is merely an impurity, and has devised a method of concentrating the radioactive matter.

The radioactive constituent in radio-tellurium and that in radium $\mathrm{E}$ are very analogous in chemical and radioactive properties, for both emit a rays, and both are deposited on a bismuth plate introduced into the active solution. In addition, I have found that the $\alpha$ rays from the two substances are identical in their power of penetration through aluminium. The radio-tellurium was obtained from Dr. Sthamer of Hamburg, in the form of a thin film of the active matter deposited on the surface of a polished bismuth plate. I was unable to detect any difference in the penetrating power of the rays from radium $E$ and radio-tellurium, although the intensity of the radiation was reduced to a few per cent. by

\footnotetext{
* Berichte d. D. Chem. Ges. p. 2285 (1902).
} 
aluminium screens. It is well known that the a rays from most of the radioactive products differ in penetrating power, and the identity of the a rays of radium $\mathrm{E}$ and radio-tellurium in this respect is a strong indication that the radioactive matter is the same in both cases. The agreement of the absorption of the rays, together with the similarity of the radiations and chemical behaviour, affords very strong evidence in favour of the identity of the two products. If this is the case the activity of the radio-tellurium must decay to half value in about one year.

It is natural here to consider the question whether the product radium $\mathrm{E}$ is also identical with the polonium discovered by Mme. Curie. Each acting constituent attaches itself to bismuth and emits only $\alpha$ rays. The test of penetrating power of the rays cannot be applied, since the polonium, as commercially sold, is usually mixed with bismuth and not, as in the case of Marckwald's radio-tellurium, deposited on a thin film on the surface. The activity observed at the surface is thus due to a rays, which have already decreased in penetrating power due to their passage through different thicknesses of bismuth. The a rays from polonium in consequence appear to be more readily absorbed than those from radium $\mathrm{E}$, but it is not unlikely that the difference observed may be due entirely to the different experimental conditions in the two cases. Mme. Curie states that the activity of polonium decays slowly with the time, and mentions: that one specimen lost half its activity in eleven months. The rate of decay of activity is about the same as that deduced from the product radium $\mathrm{E}$. Mme. Curie, in addition, observed that an active product could be separated from radium itself by precipitating bismuth added to the radium solution. This active matter present with the bismuth could be concentrated in exactly the same way as was employed for the polonium obtained directly from a solution of pitchblende. Giesel long ago observed that bismuth was made active when placed in a radium solution, and considered that polonium was in reality "induced bismuth." The product removed on the bismuth must in both eases have been radium $\mathrm{E}$, so that we have here direct evidence that polonium and radium $\mathrm{E}$ exhibit similar chemical properties.

In the original paper giving an account of the discovery of polonium, Mme. Curie states that the active matter could be concentrated to some extent by heating the active sulphide in a vacuum. The active sulphide was more volatile than the bismuth, and was deposited on portions of the glass tube between $300^{\circ} \mathrm{C}$. and $350^{\circ} \mathrm{C}$. On the other hand, I have 
shown that radium $E$ depositer on a platinum plate is not appreciably volatile until a temperature of nearly $1000^{\circ} \mathrm{C}$. It is intended to examine this point still further in order to see if this difference of behaviour is only apparent or real.

The experiments as a whole are, I think, best explained on the view that polonium and radio-tellurium both contain the same radioactive constituent, which is the fifth disintegration product of radium. The most definite method of settling the matter is to compare the rates of decay of the activity of the three active substances, and experiments of this character are already in progress.

It would be of scientific value to isolate the product radium $D$ from pitchblende, for in many respects it would be as useful scientifically as radium itself. Its activity in the pure state, measured by the $\beta$ rays, would be about 25 times that of radium, and the rate of change of its activity is sufficiently slow to be neglegible in most experiments.

Experiments are in progress to see whether a simple method can be found for separation of radium D from pitchblende*.

McGill University, Montreal, Aug. 25, 1904.

IXIV. On Saturation Currents in Ionization. By GEorGe W. Waluzer, M.A., A.R.C.Se., Fellow of Trinity College, Cambridge, Lecturer on Physics in the University of Glasgout.

$\checkmark$ WE theory and measurement of saturation currents forms the basis of much important work on the action of ionizing agents.

The fact that, when a current passes through an ionized ges between two plates, a stage is reached when a considerable increase of the potential-difference between the plates gives practically no increase of current, is explained on the simple

* Mr. B. Boltwood, of New Haven, Conn., very kindly forwarded me, a few days ago, a specimen of radionctive lead, which he had separated from pitchblende four months before. This lead gave out an unusually large proportion of $\beta$ compared with \& rays, and the total amount of $\beta$ rays from it was about the same as from the uranium present in the pitchblende from which it was separated. On dissolving the lead, some of the $\alpha$ ray activity was removed on a bismuth plate. I think that it is probable that the lead contains the product radium $\mathbf{D}$. These results suggest that Hoffmann, whose earlier work on radio-lead was subjected to much criticism, was probably right in believing that he had separated a new radioactive constituent with the lead, the activity of which did not die away with the time.

$\dagger$ Communicated by the Author. 